\title{
Expression and diagnostic use of recombinant $M$ protein of the porcine reproductive and respiratory syndrome virus
}

\author{
Jitka Frölichová1, Dobromila Molinková ${ }^{1,3}$, Markéta Sedlinskáa $^{2}$, Vladimír Celer $^{1,3}$ \\ University of Veterinary and Pharmaceutical Sciences Brno, Faculty of Veterinary Medicine, \\ ${ }^{1}$ Department of Infectious Diseases and Microbiology, ${ }^{2}$ Clinic of Horse Diseases, \\ ${ }^{3}$ CEITEC - Central European Institute of Technology, Brno, Czech Republic
}

Received August 15, 2016

Accepted January 26, 2017

\begin{abstract}
Matrix $\mathrm{M}$ protein combined with nucleocapsid $\mathrm{N}$ protein could be a promising combination of virus antigens for diagnosing the porcine reproductive and respiratory syndrome. The goal of this work was to express the recombinant $\mathrm{M}$ protein of the porcine reproductive and respiratory syndrome virus in Escherichia coli cells and compare its serological reactivity with the N protein of the virus. The gene coding for the M protein was cloned into the pDest 17 vector. The resulting protein was purified by metalochelating affinity chromatography. Recombinant M protein was applied as an antigen in immunoblot test and compared on a panel of porcine sera with $\mathrm{N}$ protein based IDEXX test. Of 120 examined samples, the majority (78.3\%) gave identical results using both compared tests. From the group of discrepant results, IDEXX test identified considerably more positive sera $(17.5 \%)$ than $\mathrm{M}$ protein based test $(4.2 \%)$. The main contribution of the work is finding that although IDEXX test proved to be more sensitive than M protein based test, $4.2 \%$ of sera would escape detection by serological test based on N protein. Further development and purification of the $\mathrm{M}$ protein for the use in Enzyme Linked Immunosorbent Assay format test could increase the performance of serological testing.
\end{abstract}

PRRS, pigs, matrix protein, expression, E. coli, serology

The porcine reproductive and respiratory syndrome virus (PRRSV) causes one of the most threatening diseases for pig industry world-wide. Infection of pigs by PRRSV is characterized by late-term abortions, high incidence of stillborn and mummified piglets, and respiratory disorders in suckling, weaned, and growing pigs (Hopper et al. 1992; White 1992).

The porcine reproductive and respiratory syndrome virus is a small, enveloped virus with positive-strand ribonucleic acid (RNA) molecule of approximately $15 \mathrm{~kb}$ in length and has been classified in the genus Arterivirus, family Arteriviridae, in the order Nidovirales (Conzelman et al. 1993; Cavanagh 1997). Its genome includes ten overlapping open reading frames (ORFs) - 1a, 1b, 2a, 2b, 3, 4, 5a, 5, 6, and 7, coding appropriate viral proteins. The virus particle contains three major structural proteins, a glycosylated envelope protein (GP5) of $25 \mathrm{kDa}$, an unglycosylated membrane protein (M) of $18 \mathrm{kDa}$, and nucleocapsid protein $(\mathrm{N})$ of $15 \mathrm{kDa}$, encoded by ORFs 5, 6 and 7, respectively (Meulenberg et al. 1993; Meulenberg et al. 1995b; Meng et al. 1996; Wu et al. 2001).

Infection of pigs by the PRRS virus induces the production of PRRSV-specific antibodies. First produced are antibodies directed against the nucleocapsid protein N, followed by antibodies against the membrane protein $\mathrm{M}$, and the last produced are antibodies directed against the envelope protein GP5. Antibody response to $\mathrm{N}$ and $\mathrm{M}$ proteins is stronger than to the GP5 protein (Nels on et al. 1994).

At present, several Enzyme Linked Immunosorbent Assay (ELISA) tests are commercially available to diagnose the disease. Serological diagnostics of PRRS infection are mostly

Address for correspondence:

Vladimír Celer

Department of Infectious Diseases and Microbiology

Faculty of Veterinary Medicine

University of Veterinary and Pharmaceutical Sciences Brno

Palackého tř. 1946/1, 61242 Brno, Czech Republic

http://actavet.vfu.cz/ 
based on the virus nucleocapsid protein because specific antibodies against the $\mathrm{N}$ protein are produced early during a PRRS infection in high titres (Meulenberg et al. 1995a). Nonetheless, serological tests based on the $\mathrm{N}$ antigen frequently display nonspecific reactivity leading to inaccurate diagnosis. A combination of tests based on different antigens would therefore be beneficial to improve the accuracy of PRRS diagnostics. The M protein is one of the most conserved structural proteins of the PRRS virus (Kapur et al. 1996). Antibodies specific to the $\mathrm{M}$ protein are abundantly expressed in vivo and appear early in the course of infection similarly as antibodies against the nucleocapsid protein (Meng et al. 1995; Loemba et al. 1996).

The inclusion of $\mathrm{M}$ protein in serological diagnostic tests could considerably increase the specificity and sensitivity of the diagnostic tests used. The main reason why this protein is not practically used in routine diagnostics are the difficulties in its recombinant expression. M protein is highly hydrophobic, moreover it contains high incidence of aminoacid residues which display a significant difference in codon usage between viral and prokaryotic organisms. Appropriate tRNAs are thus rare in Escherichia coli cells and their depletion usually leads to a premature termination of proteosynthesis. Even in the yeast expression systems, the expression of $M$ protein is difficult and results in a very low yield (Qian et al. 2003).

The aim of this work was to express the M protein in E. coli cells and to determine its diagnostic value on a panel of pig sera with a known PRRS status. Recombinant M protein could also be used for further PRRSV studies or in development of serological diagnostic assays.

\section{Materials and Methods}

\section{Serum samples}

Evaluation of serological reactivity of the recombinant M protein of the PRRS virus and comparison of sensitivity and specificity of serological test was performed on a panel of 120 swine sera originating from farms with different statuses to PRRS infection.

Blood samples were collected from nine farms from May 2006 to January 2009. All sera including control positive and negative sera were checked for PRRS specific antibodies by ELISA test HERDCHEK* PRRS X3 (IDEXX Laboratories, Inc., Maine, USA).

\section{Cloning and expression vector construction}

For the cloning of the PRRSV ORF 6 gene, appropriate gene fragment was amplified from the genomic RNA of the vaccine virus strain - Porcilis ${ }^{\circledR}$ PRRS (Intervet International B. V., Boxmeer, The Netherlands) by polymerase chain reaction (PCR). Viral RNA was extracted by NucleoSpin ${ }^{\circledR}$ RNA II kit (MACHEREY-NAGEL GmbH \& Co. $\mathrm{KG}$, Büren, Germany), according to the instructions of the manufacturer. Resulting RNA was eluted in RNasefree water and immediately used for amplification by QIAGEN ${ }^{\circledR}$ OneStep RT-PCR Kit (QIAGEN GmbH, Hilden, Germany).

Primers were designed according to sequences of genotype IPRRS virus published in the GenBank(Meulenberg et al. 1993). Primers were designed so that the sense primer contained CACC sequence allowing directional TOPO cloning into $\mathrm{pENTR}{ }^{\mathrm{TM}} / \mathrm{SD} / \mathrm{D}-\mathrm{TOPO}^{\mathbb{R}}$ Vector (Invitrogen, Carlsbad, California, USA). Stop codon was included within the antisense primer. The ORF 6 gene was amplified using sense CACCGGAGGCCTAGACGATTT and antisense primer TTACCGGCCATACTTGACGAGG. In order to verify specificity and correct orientation of the cloned insert, both strands of $\mathrm{pENTR}^{\mathrm{TM}}$ Vector were sequenced using M13 primers (Macrogen Europe, Amsterdam, Netherlands). Resulting deoxyribonucleic acid (DNA) sequences were analyzed using the software Geneious 9.0.5.

For expression, the ORF 6 gene was subcloned from pENTR ${ }^{\mathrm{TM}}$ Vector to pDest17 ${ }^{\mathrm{TM}}$ Gateway $^{\circledR}$ Vector (Invitrogen, Carlsbad, California, USA) by site-specific recombination according to the manufacturer's instructions. Transcription and translation of recombinant proteins in pDest $17^{\mathrm{TM}}$ vector was under the control of bacteriophage $\mathrm{T} 7$ transcription and translation signals. A DNA insert was positioned downstream and in frame with a sequence that encoded the $\mathrm{N}$-terminal polyhistidine.

\section{Protein expression}

Expression studies were done in different E.coli strains: BL21-CodonPlus (DE3)-RIPL (Stratagene, La Jolla, CA, USA), BL21(DE3)pLysS (Invitrogen, Carlsbad, California, USA), BL21(DE3)pLysE (Invitrogen, Carlsbad, California, USA) and BL21-AI (Invitrogen, Carlsbad, California, USA) chemically competent cells. Randomly 
chosen colonies of bacteria cells were cultivated in $20 \mathrm{ml}$ LB-medium supplemented with antibiotics $(100 \mu \mathrm{g} / \mathrm{ml}$ ampicillin and $50 \mu \mathrm{g} / \mathrm{ml}$ chloramphenicol for RIPL cells, $100 \mu \mathrm{g} / \mathrm{ml}$ ampicillin and $34 \mu \mathrm{g} / \mathrm{ml}$ chloramphenicol for pLysS and pLysE cells or $100 \mu \mathrm{g} / \mathrm{ml}$ ampicillin for BL21-AI cells). The expression of recombinant protein was induced by adding isopropyl- $\beta$-D-thiogalactoside (IPTG) to a final concentration of $1 \mathrm{mM}$ (RIPL, pLysS, and pLysE cells) or $0.02 \%$ L-arabinose (BL21-AI cells) for $4 \mathrm{~h}$ at $37^{\circ} \mathrm{C}$. Aliquots of $300 \mu 1$ of different bacterial clones were analyzed by SDS-PAGE to estimate protein expression.

For large-scale expression, a fresh overnight culture of $E$. coli cells carrying recombinant plasmid was diluted 1:50 in 21 of fresh LB-medium supplemented with $100 \mu \mathrm{g} / \mathrm{ml}$ ampicillin and $50 \mu \mathrm{g} / \mathrm{ml}$ chloramphenicol and grown to optical density $\mathrm{OD}_{600} 0.5$ at $37^{\circ} \mathrm{C}$ at a shaking speed of $250 \mathrm{rpm}$. The expression of recombinant protein was induced by $1 \mathrm{mM}$ IPTG for $4 \mathrm{~h}$ at $37^{\circ} \mathrm{C}$. Cells were then pelleted at $4500 \mathrm{~g}$ for $15 \mathrm{~min}$. The pellet was stored at $-20^{\circ} \mathrm{C}$ until use.

\section{Purification of recombinant $M$ protein}

Recombinant $\mathrm{M}$ protein was purified by immobilized-metal affinity chromatography (IMAC) using polyhistidine tag from insoluble fraction of bacterial lysate under denaturing conditions.

Bacterial cell pellet was resuspended in $40 \mathrm{ml}$ of Tris lysis buffer $(20 \mathrm{mM}$ Tris $\mathrm{pH} 7.8,1 \mathrm{M}$ sodium chloride and $0.1 \%$ Tween 20$)$ with $100 \mu \mathrm{g} / \mathrm{ml}$ lysosyme. The cells were disrupted by five sonication cycles $(40 \%$ amplitude, $25 \mathrm{~s}$ each) separated by $2 \mathrm{~min}$ intervals on ice to avoid heating of the material. Inclusion bodies were separated by centrifugation $(4700 \mathrm{~g} / 25 \mathrm{~min})$ at $4{ }^{\circ} \mathrm{C}$. Pellet was resuspended in $40 \mathrm{ml}$ of denaturing Tris buffer $(20 \mathrm{mM}$ Tris pH 7.8, 1 M sodium chloride, $0.1 \%$ Tween 20 and $8 \mathrm{M}$ urea) supplemented by $5 \mathrm{mM}$ imidazole and incubated for $1 \mathrm{~h}$. Recombinant M protein was purified from contaminating proteins using Ni-NTA Agarose (QIAGEN GmbH, Hilden, Germany) column. The column was loaded with bacterial lysate with Ni-NTA Agarose and allowed to pass through. Washing was performed using $100 \mathrm{ml}$ of denaturing Tris buffer containing $20 \mathrm{mM}$ imidazole. Bound protein was eluted using denaturing Tris buffer with $300 \mathrm{mM}$ imidazole in a total volume of $10 \mathrm{ml}$. The eluate was collected in $1 \mathrm{ml}$ fractions.

Aliquots of the protein were run on sodium dodecylsulphate polyacrylamide gel electrophoresis (SDS-PAGE) to analyze their purity. The concentration of recombinant protein was determined spectrophotometrically $\left(\mathrm{OD}_{280}\right)$. Fractions containing the pure $\mathrm{M}$ protein were pooled and stored at $-20{ }^{\circ} \mathrm{C}$ until used.

\section{SDS-PAGE and immunoblot}

Analyzed aliquots of bacterial cell lysate or recombinant protein were mixed with a Laemmli sample buffer and heated to $95{ }^{\circ} \mathrm{C}$ for $4 \mathrm{~min}$. Protein mixture was then separated on a $12 \%$ resolving and $4 \%$ stacking polyacrylamide gel in Tris-glycine buffer and stained with Coomassie Brilliant Blue. For immunoblotting, separated proteins were blotted onto the nitrocellulose membrane $\left(110 \mathrm{~V}\right.$ for $1 \mathrm{~h}$ at $\left.4{ }^{\circ} \mathrm{C}\right)$.

The presence of recombinant protein was determined by incubation with monoclonal anti-poly histidine antibody (Sigma-Aldrich, Saint Louis, Missouri, USA) diluted 1:3000 in T-PBS (phosphate buffered saline with $0.5 \mathrm{M}$ sodium chloride and $1 \%$ Tween 20 ) with $3 \%$ nonfat dry milk.

Purified recombinant protein was applied as antigen in immunoblot for detection of $\mathrm{M}$ specific antibodies in swine sera. Nitrocellulose strips were blocked with 3\% nonfat dry milk in phosphate buffered saline (PBS) $\mathrm{pH} 7.3$ for $1 \mathrm{~h}$ and then incubated with PRRSV positive or negative sera diluted 1/400 in T-PBS with 3\% nonfat dry milk for $1 \mathrm{~h}$. Bound antibody was detected by incubation with anti-pig IgG conjugated with alkaline phosphatase (Sigma-Aldrich, Saint Louis, Missouri, USA) diluted 1:30 000 in T-PBS with 3\% nonfat dry milk for $1 \mathrm{~h}$. The reaction was then made visible with a BCIP ${ }^{\circledR} / \mathrm{NBT}$ Solution (Sigma-Aldrich, Saint Louis, Missouri, USA). Serum was identified as negative when no visible colour signal was observed on nitrocellulose strip.

\section{Serological reactivity of $M$ protein}

All tested swine sera were examined by ELISA test HERDCHEK* PRRS X3 (IDEXX Laboratories, Inc., Maine, USA) according to the manufacturer's instructions to determine their PRRS true status. Subsequently all sera were examined by recombinant $\mathrm{M}$ protein based immunoblot to evaluate diagnostic sensitivity and specificity of recombinant antigen.

\section{Results}

\section{Cloning and expression vector construction}

The 522 bp long fragment of ORF 6 gene was RT-PCR amplified from genomic RNA of PRRS virus strain and successfully cloned into $\mathrm{pENTR} \mathrm{T}^{\mathrm{TM}}$ Vector by TOPO cloning. Resulting DNA construct was sequenced to ensure correct orientation of cloned DNA fragment. Then, the ORF 6 gene was transferred from pENTR ${ }^{\mathrm{TM}}$ Vector to $\mathrm{pDest}^{\mathrm{TM}} 17$ Vector to generate the expression vector. 
Protein expression and purification

Expression of the recombinant membrane protein was tested in four different $E$. coli strains: BL21-CodonPlus (DE3)-RIPL, BL21(DE3)pLysS, BL21(DE3)pLysE and BL21-AI cells. The $M$ protein was successfully expressed in BL21-CodonPlus (DE3)-RIPL competent cells only.

Molecular weight of the expressed recombinant M protein was estimated to be $21 \mathrm{kDa}$ (with $\mathrm{N}^{\prime}$ terminal polyhistidine). SDS-PAGE analysis has shown that the recombinant protein of expected size was expressed following induction (Fig. 1).

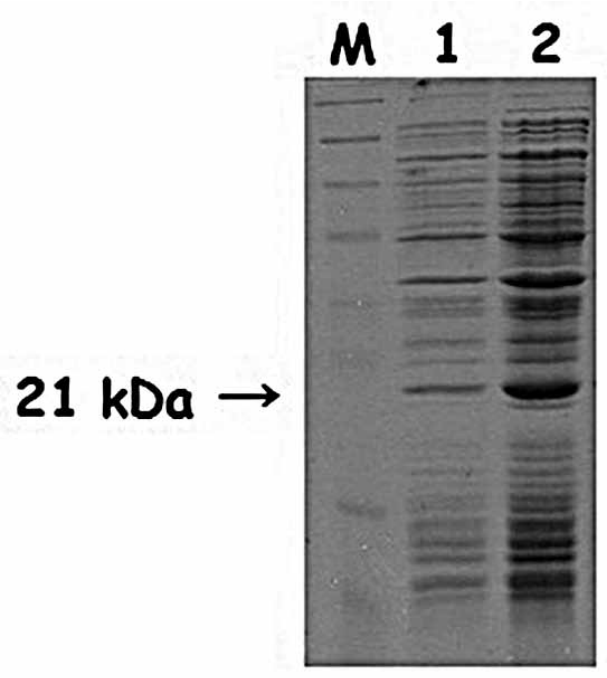

Fig. 1. SDS-PAGE analysis of recombinant M protein.

M - Prestained Protein Marker (New England Biolabs, Ipswich, Massachusetts, USA), 1 - bacterial lysate before induction, 2 - bacterial lysate after induction.

Large volume production of recombinant protein was expressed in BL21-CodonPlus (DE3)-RIPL E. coli cells. Recombinant protein was present in the insoluble fraction of bacterial cells only.

Protein was purified from insoluble fraction of bacterial lysate under denaturing conditions (8 M urea) using Ni-NTA Agarose. The yield of recombinant M protein was $4 \mathrm{mg} / \mathrm{l}$ of bacterial culture.

\section{Serological reactivity of $M$ protein}

Recombinant $M$ protein of the PRRS virus was used as antigen in immunoblot for detection of PRRSV specific antibodies in the swine sera. The amount of protein used per membrane stripe was $0.24 \mu \mathrm{g}$. Positive and negative control sera were regularly included in the testing schedule. A total of 120 swine sera from PRRSV-positive and PRRSV-negative farms were examined by $\mathrm{M}$ protein immunoblot and the comparison with PRRS status determined by IDEXX test is summarized in Table 1. Both used tests gave identical results (positive or negative) in 94 serum samples (78.3\%). Fifty-five (45.8\%) samples were identified as positive by both tests, 39 (32.5\%) negative by both tests. Twenty-six of the tested sera (21.7\%) gave discrepant results. 
Table 1. Comparison of serological reactivity of M protein and IDEXX test.

\begin{tabular}{llcrr}
\hline & IDEXX & & \\
\hline \multirow{4}{*}{ M protein } & & Positive & Negative & Total \\
& Positive & $55(45.8 \%)$ & $5(4.2 \%)$ & $60(50 \%)$ \\
& Negative & $21(17.5 \%)$ & $39(32.5 \%)$ & $60(50 \%)$ \\
& Total & $76(63.3 \%)$ & $44(36.7 \%)$ & $120(100 \%)$ \\
\hline
\end{tabular}

\section{Discussion}

Serological tests for PRRS diagnostics are in a majority of cases based on the nucleocapsid $\mathrm{N}$ protein. Although the PRRS virus nucleoprotein alone is considered as a reliable antigen, in some cases nonspecific reactions can be seen and enrichment of serological testing by additional antigens could be beneficial. Serological tests never reach $100 \%$ accuracy, and the PRRS ELISA tests are no exception. In populations of negative pigs, even $1 \%$ of positive animals misdiagnosed by the ELISA test lead to considerable economic impacts.

The $\mathrm{M}$ protein is an abundant component of PRRS virus membrane proteins and a serological diagnostic test based on this virus antigen could considerably increase the specificity and sensitivity of used diagnostic tests. The aim of our work was to express the M protein in E. coli cells and to compare its diagnostic value with tests based on the nucleocapsid protein as the antigen.

The possible advantage of using this particular virus structure is that it is considered as a highly conserved structural protein of the PRRSV (Meng et al. 1995). Moreover, antibodies against the M protein appear approximately within two weeks after PRRS infection (Loemba et al. 1996; Plana Duran et al. 1997; Kwang et al. 1999).

As the M protein is not glycosylated, expression in the $E$. coli system offers a possibility of easy and relatively cheap production of a suitable amount of recombinant protein.

Because of the hydrophobic nature of the $\mathrm{M}$ protein molecule which contains three transmembrane segments, 84-residue C-terminal endodomain, and a high percentage of aminoacids using rare tRNAs for translation (arginine and other amino acids with different codon biases), expression was performed in different E. coli cells. Expression in our experiments has reached $4 \mathrm{mg} / \mathrm{l}$ of bacterial culture in E. coli BL21-CodonPlus (DE3)-RIPL cells only. We can thus conclude that a successful expression of the M protein depends on the supply of rare tRNAs. The expression in other cells leads to the exhaustion of the intracellular pool of rare tRNAs and to a premature termination of the nascent polypeptide chain.

Because of the hydrophobic nature of $\mathrm{M}$ protein, expression in other expression systems could be beneficial. Nonetheless, attempts to express the M protein in the baculovirus were not successful (Plana Duran et al. 1997) or the protein was expressed in a very limited amount (Kreutz and Mengeling 1997). Even in the Pichia pastoris cells the expression of $\mathrm{M}$ protein is difficult and results in a very low yield. Only substantial changes of the genetic code allowed a high expression of the M protein (Qian et al. 2003).

To assess the potential of the diagnostic use of the M protein, diagnostic sensitivity and specificity was compared with a commercially available ELISA test based on the traditional nucleocapsid protein of PRRS virus. The low yield of recombinant protein caused insufficient purification level for use in ELISA test and therefore, immunoblot was used for the $\mathrm{M}$ protein evaluation.

Of the 120 examined samples, the majority $(78.3 \%)$ gave identical results using both compared tests. Twenty-six of the tested sera $(21.7 \%)$ gave discrepant results. From the group of discrepant results, IDEXX test identified more positive sera $(17.5 \%)$ than 
M protein based test (4.2\%). The sensitivity of $\mathrm{N}$ based ELISA test is thus higher compared to immunoblot; on the other hand, immunoblot is usually considered as highly specific.

Although the difference between sensitivities of both tests is most likely due to the generally higher sensitivity of ELISA tests, part of IDEXX test positive and M protein negative results can be attributed to a better performance of the nucleocapsid virus protein as antigen in IDEXX test. Antibodies against N protein are elicited early in the course of infection and can be detected as early as one week following infection (Loemba et al. 1996). In our study, sera originated from swine farms with different PRRS status and most likely at least part of the animals were infected only recently and were thus showing only $\mathrm{N}$-specific antibodies.

Furthermore, $\mathrm{N}$ protein is the most abundant (Meulenberg et al. 1995b; Dea et al. 2000) and most immunogenic viral protein which also accounts for the better results obtained by IDEXX ELISA test.

Despite this, more than $4 \%$ of sera were found to be positive by the $M$ protein but negative by ELISA test which represents $19 \%$ of sera from the group with discrepant results. These positive animals would escape detection by a routine ELISA test check. Further development of the M protein antigen for use in ELISA format test could thus increase the performance of PRRS serological testing.

\section{Acknowledgements}

This work was supported by the Grant Agency of the Ministry of Education, Youth and Sports of the Czech Republic, COST grant no. LD12001; Internal Grant Agency of VFU Brno No. 107/2015/FVL; and by project QJ1210120 funded by National Agency for Agricultural Research (NAZV).

\section{References}

Cavanagh D 1997: Nidovirales: a new order comprising Coronaviridae and Arteriviridae. Arch Virol 142: $629-633$

Conzelman KK, Visser N, Van Woensel P, Thiel HJ 1993: Molecular characterization of porcine reproductive and respiratory syndrome virus, a member of the arterivirus group. Virology 193: 329-339

Dea S, Gagnon CA, Mardassi H, Pirzadeh B, Rogan D 2000: Current knowledge on the structural proteins of porcine reproductive and respiratory syndrome (PRRS) virus: comparison of the North American and European isolates Arch Virol 145: 659-688

Hopper SA, White ME, Twiddy N 1992: An outbreak of blue-eared pig disease (porcine reproductive and respiratory syndrome) in four pig herds in Great Britain. Vet Rec 131: 140-144

Kapur V, Elam MR, Pawlovich TM, Murtaugh MP 1996: Genetic variation in porcine reproductive and respiratory syndrome virus isolates in midwestern United States. J Gen Virol 77: 1271-1276

Kreutz LC, Mengeling WL 1997: Baculovirus expression and immunological detection of the major structural proteins of porcine reproductive and respiratory syndrome virus. Vet Microb 59: 1-13

Kwang J, Zuckermann F, Ross G, Yang S, Osorio F, Liu W, Low S, 1999: Antibody and cellular immune responses of swine following immunization with plasmid DNA encoding the PRRS virus ORF's 4, 5, 6 and 7. Res Vet Sci 7: 197-199

Loemba HD, Mounir S, Mardassi H, Archambault D, Des S, 1996: Kinetics of humoral immune response to the major structural proteins of the porcine reproductive and respiratory syndrome virus. Arch Virol 141: 751-761

Meng XJ, Paul PS, Halbur PG, Lum MA 1995: Phylogenetic analyses of the putative M (ORF 6) and N (ORF 7) genes of porcine reproductive and respiratory syndrome virus (PRRSV): implication for the existence of two genotypes of PRRSV in the U.S.A. and Europe. Arch Virol 140: 745-755

Meng XJ, Paul PS, Morozov I, Halbur PG 1996: A nested set of six or seven subgenomic mRNAs is formed in cells infected with different isolates of porcine reproductive and respiratory syndrome virus. J Gen Virol 77: $1265-1270$

Meulenberg JJ, Hulst MM, De Meijer EJ, Moonen PL, Den Besten A, De Kluyver EP, Wensvoort G, Moormann RJM 1993: Lelystad virus, the causative agent of porcine epidemic abortion and respiratory syndrome (PEARS), is related to LDV and EAV. Virology 192: 62-72

Meulenberg JJ, Bende RJ, Pol JM, Wensvoort G, Moormann RJ 1995a: Nucleocapsid protein N of Lelystad virus: expression by recombinant baculovirus, immunological properties, and suitability for detection of serum antibodies. Clin Diag Lab Immunol 2: 652-656

Meulenberg JJ, Petersen-den Besten A, de Kluyver EP, Moormann RJ, Wensvoort G 1995b: Characterization of proteins encoded by ORFs 2 to 7 of Lelystad virus. Virology 206: 155-163 
Nelson EA, Christopher-Hennings J, Benfield DA 1994: Serum immune response to the proteins of porcine reproductive and respiratory syndrome (PRRS) virus. J Vet Diag Invest 6: 410-415

Plana Duran J, Climent I, Sarraseca J, Urnizal A, Cortes E, Vela C, Casal JI 1997: Baculovirus expression of proteins of porcine reproductive and respiratory syndrome virus strain Olot/91: Involvement of ORF 3 and ORF 5 proteins in protection. Virus Genes 14: 19-29

Qian P, Li X, Tong G, Chen H 2003: High-level Expression of the ORF6 Gene of Porcine Reproductive and Respiratory Syndrome Virus (PRRSV) in Pichia pastoris. Virus Genes 27: 189-196

White MEC 1992: The clinical signs and symptoms of blue-eared pig disease (PRRS). Pig Vet J 28: 62-68

Wu WH, Fang Y, Farwell R, Steffen-Bien M, Rowland RR, Christopher-Hennings J, Nelson EA 2001: A 10-kDa structural protein of porcine reproductive and respiratory syndrome virus encoded by ORF2b. Virology 287: 183-191 